\title{
Exploration of Engineering Education Method in Electrical Specialty Xue Jian $^{1}$, Bai Yan ${ }^{2, *}$, Zhu He ${ }^{3}$ \\ ${ }^{1}$ Electrical and Information Engineering of Beihua University \\ ${ }^{2}$ Metalworking Training Center of Beihua University. \\ ${ }^{3}$ Mining Services Division of Jilin Group \\ *Corresponding Author
}

Keywords: CDIO; talent training; engineering education; Electrical class

\begin{abstract}
According to CDIO's two most important documents "CDIO syllabus" and "CDIO standards" and CDIO's three general objectives, Combined with our school electrical students learning situation, This paper puts forward the CDIO project education program which is suitable for the current situation of students in our school, and puts it into the classroom teaching and practice activities. The actual effect shows that the scheme can reflect the core connotation of the CDIO mode to cultivate talents. It is of great practical significance to cultivate talents with engineering practice ability.
\end{abstract}

\section{CDIO Connotation}

The two main questions facing any attempt to improve engineering education are: 1 . How can students have sufficient knowledge and ability to solve practical problems? 2. How can students have sufficient knowledge and ability to solve practical problems? In other words, we should make the students have the ability to think about "what" and then "how to do" the ability. Start from these two issues, CDIO developed the CDIO's two most important documents "CDIO syllabus" and "CDIO standard". At the same time, CDIO also put forward three general goals, requiring students to: (1) more in-depth understanding of the basic knowledge of technology; (2) leading new products, processes or systems development and operation; (3) understanding of research and technology development on society importance and strategy influences. That is, CDIO model to cultivate a better technical knowledge, can lead the development and operation of innovation and social and historical responsibility of the engineers. Combined with CDIO, our school electrical college automation professional introduction of the concept of engineering education, and achieved good results. The Basic Idea of CDIO Engineering Education Reform is shown in Fig.1.

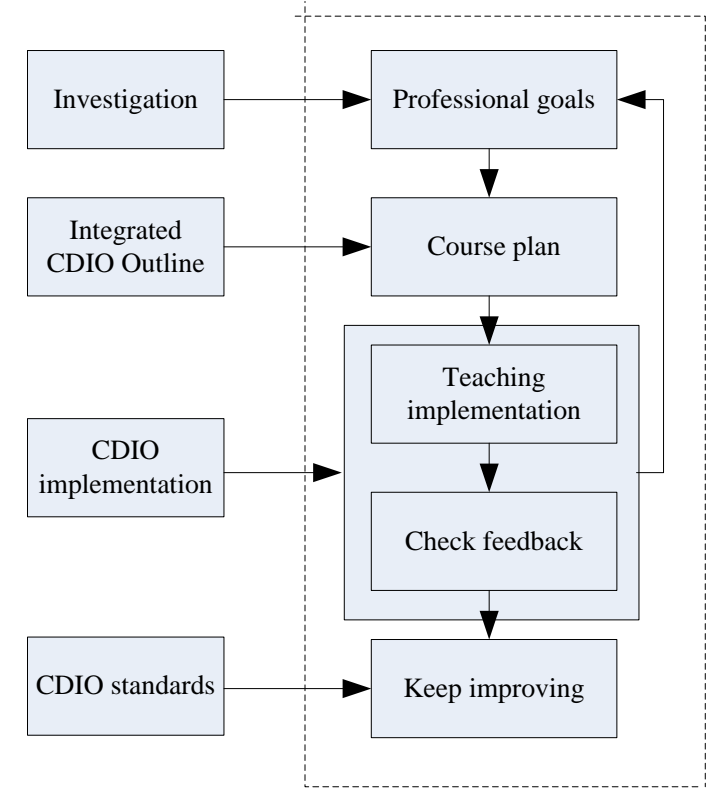

Fig.1 The Basic Idea of CDIO Engineering Education Reform 


\section{CDIO Solution}

CDIO syllabus and UNESCO's four pillars of education (learn to learn, learn to do, learn to cooperate, learn to do things) and various countries and regions of different engineering education certification standards have done a detailed comparison, have better Fit, reflecting the times of engineering practice and education reform practice of engineering education training objectives. In terms of achieving the training objectives, the CDIO standard requires the integration of the curriculum system (integrated curriculum plan) according to the CDIO syllabus. The teaching process should give students a dual effect (integrated culture) of knowledge, ability and quality training. The top-level design of the process allows students to achieve integrated learning experience and the need to establish a training-based assessment and improvement system (continuous improvement).

\section{The Application of Engineering Education in Our University}

Since the CDIO engineering education reform in Shantou University in 2005, the CDIO engineering education model has spread rapidly throughout the country. Our school conforms to the CDIO reform model, participates in the reform process, and the college gives full play to the role of the active participant in reform. College in the use of laboratory equipment and other resources to give the greatest convenience, and strive for teachers for resources, the initial implementation of success. In the CDIO engineering education reform, our school teachers take the initiative to participate in various CDIO teaching reform seminar, participate in the CDIO international conference, take the CDIO teaching reform project, download the CDIO outline, the curriculum plan, the single course outline, the team Design projects and student assessment programs and other information to learn and organize, select the appropriate level for our students at the level of relevant information for research, development and implementation. After each stage of the engineering education reform, students will be surveyed and feedback to obtain their comments and comments, to improve the next stage of reform, and to organize various activities to mobilize the enthusiasm of students to participate in the reform. The specific implementation plan is shown in Fig2.

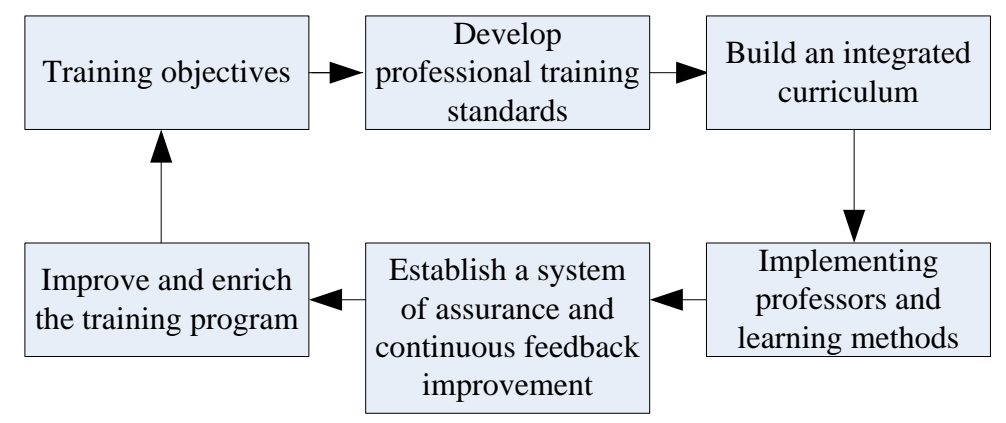

Fig2. A Case Study of the Implementation of Engineering Education in Our University

In the teaching and research activities, the organization of relevant teachers to do the project education reform documents, training sessions and seminars of the meeting records, teachers work experience memorandum, college developed reform program, CDIO syllabus, the professional curriculum and the single The outline of the course and all the documents and files of the preservation, collation and refining work, the main documents upgraded to the system norms.

In this year's freshman students, to carry out the innovation week activities, in the project, students 4 to 6 people to form a team, each team has a specific project, from the project proposition, data collection, program demonstration, specific design, project (C-D-I-O) through a complete idea, design, implementation and operation. In the reply of the innovation week, it fully embodies the great significance of this activity, not only systematically show students to achieve an initial engineering capacity, but also for students of engineering education theme opened a good start, so that each classmate Can actively participate in and understand the importance of engineering education, but also for the follow-up courses laid a good foundation. 
At the same time, a comprehensive design project has been added to effectively combine the associated course knowledge points. To make students aware of organic and associated knowledge rather than isolated knowledge. The combination of curriculum construction and practice avoids duplication of content and reduces school hours. After CDIO education reflection, on the one hand can inspire students to actively carry out critical thinking, thinking about the process of thinking is to deepen the course of learning objectives of the process; the other hand also help students to deep-level learning and asked to deepen the theory Knowledge, learning process and so on. Since the implementation of our school education project, students' practical ability and engineering practice ability has been greatly improved, the harvest is quite good.

\section{Acknowledgement}

This paper is supported by the project of BHQD 31.2016.

\section{References}

[1] GU Peihua, Bao Nengsheng, Kang Quanli, Lu Xiaohua, Xiong Guangjing, Lin Peng, Chen Yan; CDIO in China (on); Higher Engineering Education Research; 2012.3: 24-40

[2] Hu Wenlong, CDIO-based engineering inquiry teaching reform research; higher engineering education research, 2013.5: 163-168

[3] Gu Peihua, Bao Nengsheng, Kang Quanli, Lu Xiaohua, Xiong Guangjing, Lin Peng, Chen Yan; CDIO in China (below); Higher Engineering Education Research; 2012.5: 34-45

[4] Gu Xuelong, CDIO-Link Theory and Practice of Innovative Engineering Education in Tsinghua University; Higher Engineering Education Research; 2013.5: 11-23

[5] Jian Jianzhong, Xu Wensheng, Gu Xuelong, Zhu Xiaomin, Lu Yiping, E Mingcheng; from the outline of the ability to integrated curriculum system design CDIO model; Higher Engineering Education Research; 2013.1: 10-23

[6] Wang Tianbao, Cheng Weidong; Research and Practice of Innovative Engineering Talent Training Model Based on CDIO - Engineering Education Reform Practice of Chengdu Institute of Information Engineering; Higher Engineering Education Research; 2009.11: 25-31

[7] Edward F.Crawley, Charles Jian, Johan Malmqvist, Doris R..Brodeur_Crawley, Engineering Education Environment; Higher Engineering Education Research; 2008.3: 13-21 